\title{
Wavelet analysis reveals periodic oscillations in a 1700 year ice-core record from Guliya, China
}

\author{
Meixue YANG, ${ }^{1,2,3}$ Tandong YAO, ${ }^{2}$ Xiaohua GOU, ${ }^{4}$ Huijun WANG, ${ }^{3}$ \\ Thomas NEUMANN ${ }^{5}$
}

\author{
${ }^{1}$ Key Laboratory of Cryosphere and Environment, Cold and Arid Regions Environmental and Engineering Research Institute, \\ Chinese Academy of Sciences, 260 Donggang West Road, Lanzhou 730000, China \\ E-mail: mxyang@Izb.ac.cn \\ ${ }^{2}$ Institute of Tibetan Plateau Research, Chinese Academy of Sciences, Beijing 100085, China \\ ${ }^{3}$ The Nansen-Zhu International Research Center, Institute of Atmospheric Physics, Chinese Academy of Sciences, \\ Beijing 100101, China \\ ${ }^{4}$ Center for Arid Environment and Paleoclimate Research, Lanzhou University, 298 Tianshui Road, Lanzhou 730000, China \\ ${ }^{5}$ Department of Geology, University of Vermont, Burlington, VT 05405-0122, USA
}

\begin{abstract}
Ice cores contribute important records of past climate changes. As one of the thickest ice caps in central Asia, the Guliya ice cap $\left(35^{\circ} 17^{\prime} \mathrm{N}, 81^{\circ} 29^{\prime} \mathrm{E}\right)$ provides valuable information for this critical region about the past climate and environment changes. We used wavelet analysis to examine periodic temperature and precipitation oscillations over the past $\mathbf{1 7 0 0}$ years recorded in the Guliya ice core. The results show non-linear oscillations in the ice-core records, with multiple timescales. Temperature records indicate persistent oscillations with periodicities of approximately 200, 150 and 70 years. Precipitation records show significant periodicities at 200, 100, 150 and 60 years. However, the amplitude modulation and frequency vary with time. Wavelet analysis can explore these time series in greater detail and furnish additional useful information.
\end{abstract}

\section{INTRODUCTION}

The study of climate oscillations on decadal to century timescales supports important aspects of climate research. The Climate Variability and Predictability Program (CLIVAR) considers improved understanding of such oscillations as one of its three areas of special interest. According to the International Geosphere-Biosphere Program, climatechange studies can be grouped into three primary timescales: 20, 2 and $0.2 \mathrm{kyr}$. Of these, $2 \mathrm{kyr}$ is a challenging timescale because it contains decadal- to century-scale climate changes and requires relatively high-resolution proxy data. Although China has abundant historical archives, reliable climate projections back 2000 years are difficult. This is especially true in western China, due to the shortage of historical records. Therefore, proxy data such as those from ice cores and tree rings are important for examining climatic and environmental changes in western China (Thompson and others, 1989, 1995, 1997, 2000; Yao and Thompson, 1992; Yao and others, 1995, 1996, 1997, 2001, 2002; Shi and others, 1999; Yang and others, 2002; Gou and others, 2005, 2006).

Power-spectrum and maximum-entropy-spectrum analysis only provide the average periods of the whole time series. They cannot distinguish between oscillations with different phases. However, the wavelet transform can provide more information about the oscillations within the time series (Holschneider, 1995). The amplitude modulation, phase and frequency are important aspects of non-linear oscillations in a complex climate system with multiple timescales. Wavelet analysis is becoming a common tool for analyzing localized power variations within a time series. By transforming a time series into time-frequency space, one is able to determine both the dominant modes of variability and how those modes vary with time. The wavelet transform has been used for numerous studies in geophysics, including tropical convection (Weng and Lau, 1994), the El Niño-Southern Oscillation (ENSO) (Gu and Philander, 1995; Wang and Wang, 1996; Jevrejeva and others, 2003), the ENSOmonsoon systems (Torrence and Webster, 1999), atmospheric cold fronts (Gamage and Blumen, 1993), the dispersion of ocean waves (Meyers and others, 1993), wave growth and breaking (Liu, 1995) and coherent structures in turbulent flows (Farge, 1992). See Foufoula-Georgiou and Kumar (1995) for a complete description of geophysical applications, and Daubechies (1992) for a theoretical treatment of wavelet analysis. In our analysis, we use the wavelet method introduced by Torrence and Compo (1998) to examine the periodic climate oscillations over the past 1700 years recorded in the Guliya ice core.

\section{GULIYA ICE CORE}

Hansen and Lebedeff (1987) drew attention to the potential sensitivity of the Qinghai-Tibetan Plateau, China, with an average altitude of $>4500 \mathrm{~m}$, to the anticipated global warming of the next century. Ice cores drilled from several places on the Qinghai-Tibetan Plateau have been used to reconstruct climatic changes in the last few decades (Thompson and others, 1989, 1995, 1997, 2000; Yao and others, 1990, 1994, 1995, 1996, 1997, 2001, 2002; Yao and Thompson, 1992).

Thompson and others (1995) successfully retrieved three ice cores, with respective lengths of $308.7,93.2$ and $34.5 \mathrm{~m}$, from 6200-6700 ma.s.I. on the Guliya ice cap $\left(35^{\circ} 17^{\prime} \mathrm{N}\right.$, $81^{\circ} 29^{\prime} \mathrm{E}$ ), west Kunlun Shan, Qinghai-Tibetan Plateau (Fig. 1). The longest core reached bedrock at $308.7 \mathrm{~m}$. The Guliya ice cap is the largest in central Asia, with an area of $376 \mathrm{~km}^{2}$ (Yao and others, 1997). The $308.7 \mathrm{~m}$ ice core at 


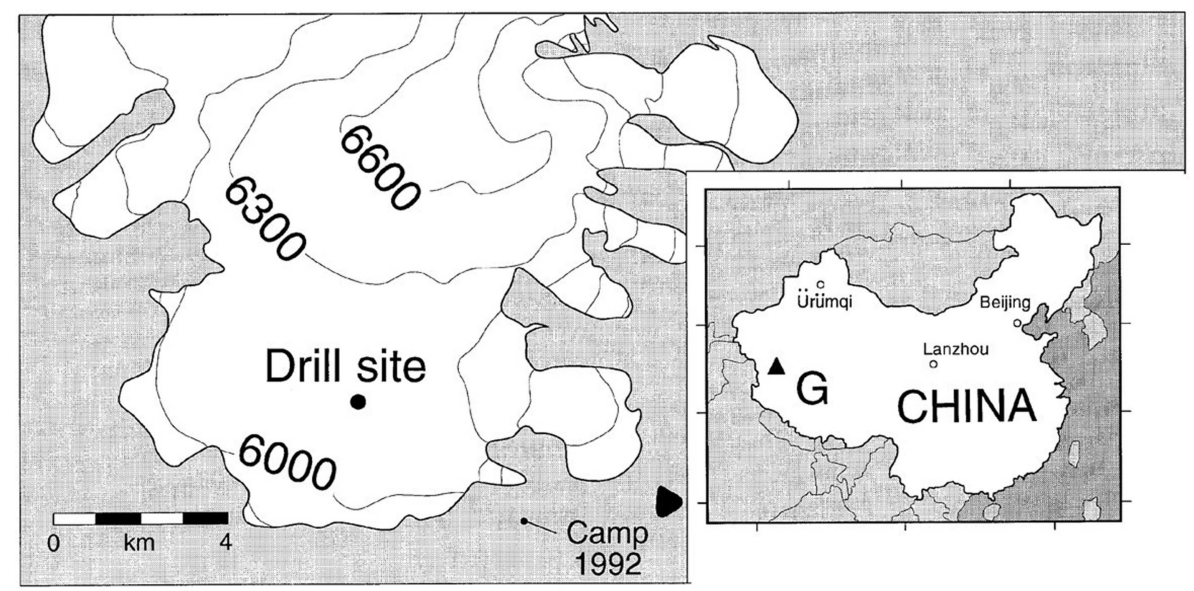

Fig. 1. The location of the Guliya (G) ice cap and the site where the $308.7 \mathrm{~m}$ Guliya ice core was drilled, at $6200 \mathrm{~m}$ a.s.l. (after Thompson and others, 1997).

6200 ma.s.l. was drilled using a mechanical corer in a dry borehole to $200 \mathrm{~m}$ depth, and using a thermal core drill with an alcohol-water mixture from $200 \mathrm{~m}$ to bedrock. The ice temperatures in the core were $-15.6^{\circ} \mathrm{C},-5.9^{\circ} \mathrm{C}$ and $-2.1^{\circ} \mathrm{C}$ at 10 and $200 \mathrm{~m}$ depth and the bottom, respectively. Visible horizontal layers exist throughout the core, with no apparent breaks. Mass-balance measurements in 1990 and 1991 indicate that the ice cap receives $\sim 200 \mathrm{~mm}$ w.e. of accumulation per year (Thompson and others, 1997; Yao and others, 1997).

Yao and others (1990) dated the Guliya ice cores by counting the distinct annual dust layers and the seasonal variations in $\delta^{18} \mathrm{O}$. Thompson and others (1995) describe the details of the field and laboratory methods used. The temperature record in the Guliya ice core is derived from $\delta^{18} \mathrm{O}$ measurements. $\delta^{18} \mathrm{O}$ in precipitation is a reliable indicator of temperature on the northern Tibetan Plateau, as described by Yao and others (1996). First, according to measurements of $\delta^{18} \mathrm{O}$ and temperature change during precipitation events and the seasonal changes of $\delta^{18} \mathrm{O}$ and temperature during several years, $\delta^{18} \mathrm{O}$ in precipitation is positively correlated with temperature, i.e. low temperature in winter corresponds to low $\delta^{18} \mathrm{O}$ value in precipitation, and high temperature in summer corresponds to high $\delta^{18} \mathrm{O}$ value in precipitation. Second, the positive correlation between $\delta^{18} \mathrm{O}$ and temperature can be expressed quantitatively. Whenever $\delta^{18} \mathrm{O}$ in precipitation increases (or decreases) by $1 \%$, temperature increases (or decreases) by about $1.6^{\circ} \mathrm{C}$ (Yao and others, 1995). In this way, we use $\delta^{18} \mathrm{O}$ measurements from the Guliya ice core to derive a time series of temperature.

The precipitation time series is derived from three sources: (1) accumulation stakes, (2) visible stratigraphy in snow pits, and (3) insoluble particulates, and both $\beta$ and tritium horizons in the Guliya ice core (Thompson and others, 1995). We estimate precipitation on the Guliya ice cap from the net accumulation between annual horizons in the ice core. As studied by Yao and others (1996), net accumulation on this ice cap approximates the actual total precipitation, since sublimation is negligible. The Guliya ice-core records have supplied data for many climatic and environmental studies (Yao and others, 1992, 1994, 1995, 1996; Li and others, 1993, 1994; Thompson and others, 1995, 1997; Yang and others, 2000).

\section{PERIODIC CLIMATE OSCILLATIONS OVER THE PAST 1700 YEARS}

Figure 2 shows the variations of $\delta^{18} \mathrm{O}$ and net accumulation (10 year average) reconstructed from the Guliya ice core for the past 1700 years. Yao and others $(1996,1997)$ examined the climatic and environmental characteristics of the Guliya ice cap from the climate variations on decadal and century timescales since the 3rd century. They concluded that the temperature varies more rapidly (shorter period cycles) than precipitation. They also reported that precipitation changes lagged behind temperature changes. Based on their work, Shi and others (1999) studied the decadal climatic characteristics recorded in the Guliya ice cap and compared the records from the Guliya ice core with historical records from eastern China. This comparison showed similar dating of

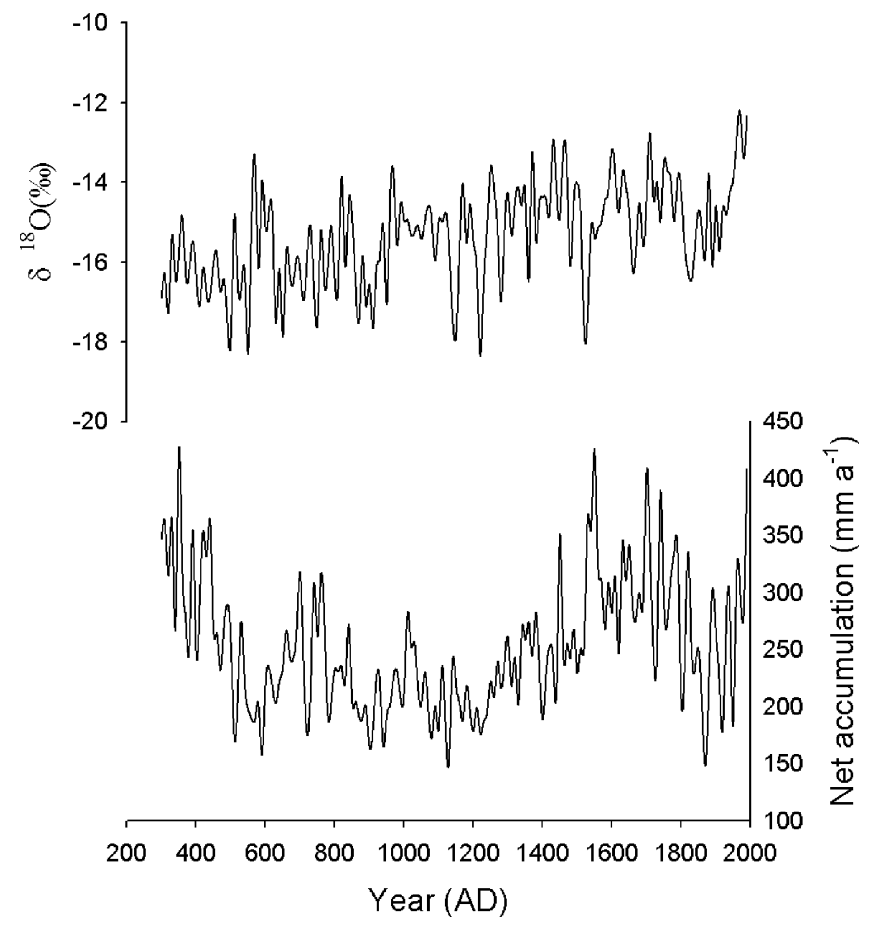

Fig. 2. Variations of the 10 year average net accumulation and $\delta^{18} \mathrm{O}$ in the Guliya ice core over the past 1700 years. 

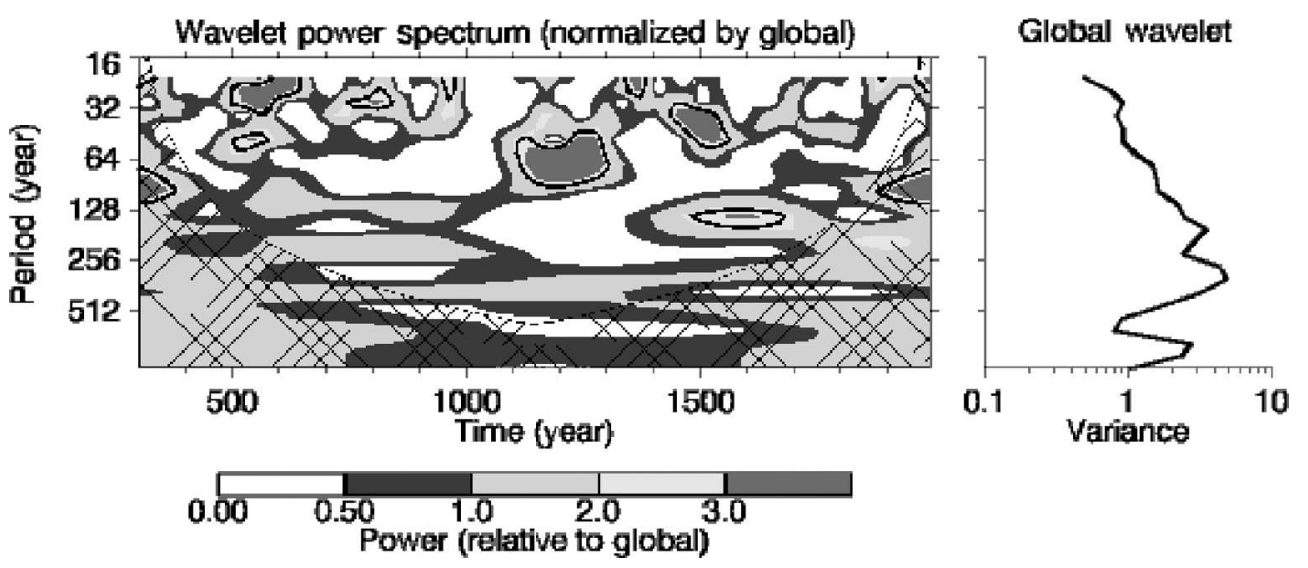

Fig. 3. Portrayal of the wavelet analysis for 10 year average temperature over the last 1700 years. The periods shown on the left indicate the wavelet power spectrum. The power has been scaled by the global wavelet spectrum (shown at right). The cross-hatched region is the cone of influence, where zero padding has reduced the variance. The black contour lines represent the $10 \%$ significance level, using the global wavelet as the background spectrum. The right plot shows the global wavelet power spectrum.

major climatic events in the ice-core record and the historical documents. Their results suggest that consistencies and similarities in climatic variation extend to the lower and mid-latitudes of central Asia.

Yao and others (1996, 1997) introduced maximum entropy spectrum analysis and highlighted the periodic oscillations recorded in the Guliya ice core over the past 2000 years. However, the maximum entropy spectrum analysis only shows the average periods over the length of the time series. By transforming the time series into timefrequency space, wavelet analysis can also determine the dominant modes of variability and how those modes vary over time.

Figure 3 shows the wavelet power spectrum for the 10 year average temperature time series using the Morlet wavelet for the past 1700 years. The cross-hatched region is the cone of influence, where zero padding has reduced the variance. The black contour lines represent the $10 \%$ significance level, using the global wavelet as the background spectrum. The global wavelet variance highlights that there is an approximately 300 year period during the past 1700 years. Around AD 600, this period length was approximately 360 years; the period length decreases and the amplitude increases towards the present. At the end of the 20th century, this period length decreased to 300 years and the amplitude was the largest. A 200 year period also exists, but only lasts to AD 1100. After AD 1700, the 200 year period appears again. A period of 100 years also exists only until AD 1100. After examining the variations of temperature and precipitation recorded in the Guliya ice core, Yao and others (1996) pointed out that AD 1100 was a key transition era. Before AD 1100, cold and dry weather prevailed. After AD 1100, temperatures rose and precipitation increased.

From AD 1100 to 1350, a 70 year cycle becomes significant (above 10\% significance level), while the 200 and 100 year periods disappeared. However, after AD 1400, the 70 year period essentially disappears, while the 150 year period is significant from AD 1400 to 1750 . This period was especially strong around AD 1600 (above 10\% significance level). Additionally, the wavelet power spectrum (Fig. 3) highlights a significant period of 40 years around AD 1500 (above 10\% significance level).
Figure 4 shows the wavelet power spectrum for 10 year average precipitation for the past 1700 years using the Morlet wavelet. The cross-hatched region is the cone of influence, where zero padding has reduced the variance. The black contour lines represent the $10 \%$ significance level, using the global wavelet as the background spectrum. Around AD 400, the precipitation records show periods around 350 years. The period length shortened and the amplitude decreased from that time forward, disappearing around AD 1100. Beginning around AD 1300, periods around 200 years become significant. Periods around 100 years are strongest from AD 1400 to 1600 (above 10\% significance level). The amplitude of the 150 year period is also large from AD 300 to 400, $\mathrm{AD} 900$ to 1200, AD 1400 to 1600, and AD 1900 to 2000. From AD 700 to 800 , the amplitude of the periods around 60 years is large and these periods appear significant (above 10\% significance level). Short periods between 20 and 30 years also strengthen from AD 300 to 500, and AD 1400 to 2000. Such periods also commonly exist in other proxy data (Taylor and others, 1992; Cook and others, 1996; Villalba and others, 1996; Baliunas and others, 1997; Biondi and others, 2000).

The wavelet power spectra of the two time series of temperature and precipitation proxy data show that some periodicities such as 200-300 years existed over the entire length of record investigated. Around AD 1500, a 100150 year periodicity is significant in both records; but for other periods (e.g. the 60-70 year cycle), although they are significant, they do not appear at the same time.

\section{CONCLUSIONS}

The power-spectrum and maximum-entropy-spectrum analysis only reveal the average periodicities for the whole time series. They do not distinguish the different phases of the oscillations. Therefore, using the power-spectrum or maximum-entropy-spectrum analysis approach is not sufficient to characterize the oscillations within the time series. The wavelet transform can highlight localized intermittent oscillations and provide more information about the oscillations within the time series (Holschneider, 1995). By transforming a time series into time-frequency space, one is able to determine both the dominant modes of variability and how those modes vary in time. 


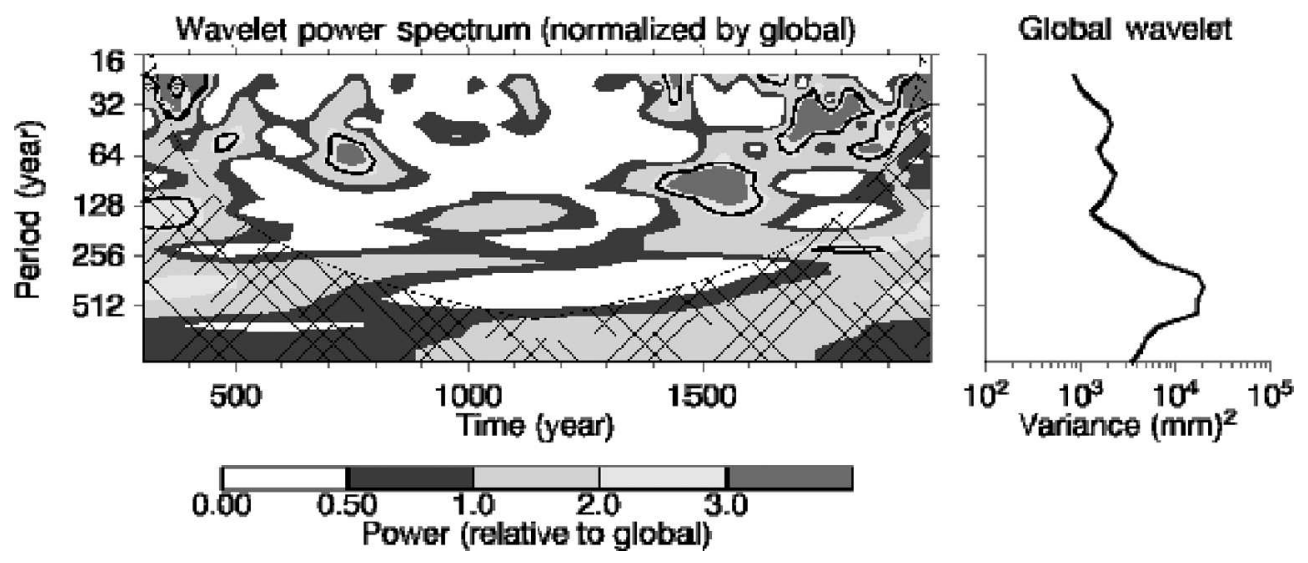

Fig. 4. Portrayal of the wavelet analysis for 10 year average precipitation for the last 1700 years. The periods shown in the left plot indicate the wavelet power spectrum. The power has been scaled by the global wavelet spectrum (shown at right). The cross-hatched region is the cone of influence, where zero padding has reduced the variance. The black contour lines represent the $10 \%$ significance level, using the global wavelet as the background spectrum. The right plot shows the global wavelet power spectrum.

The wavelet power spectrum for temperature (derived from $\delta^{18} \mathrm{O}$ measurements) using the Morlet wavelet highlighted the intermittent existence of 100 and 200 year periods. From AD 1100 to 1350, periods around 70 years appear very significant, while the 200 and 100 year periods disappear. But a period around 150 years is also evident in the past 1700 years. However, the amplitudes and the period lengths vary with time. Precipitation also shows important periods around 200 and 100 years, as well as notable periods around 150 and 60 years. Again, the amplitudes and periods vary with time.

In this paper, the existence of the above periodic oscillations is highlighted and their variations in amplitude and periodicity are also addressed. However, it is more difficult to determine the external or internal forces that cause such oscillations. What is the relationship of these oscillations to meteorological observations and other climate proxy data? Are they also significant over the same time intervals in other climate proxy data? We will try to answer these questions in a future study.

\section{ACKNOWLEDGEMENTS}

We thank the referees for valuable and constructive criticism. This research was jointly supported by the National Key Basic Research Program (2005CB422004), the Chinese National Science Foundation (40201012, 40571036, 90102005), the Innovation Group Fund (40121101), the Key Projects of the Chinese Academy of Sciences (CAS) (KZCX2-SW-118), the Century Program of CAS (2004401), the Outstanding Youth Funds of the Chinese Natural Science Foundation (40125014), the Chinese Postdoctoral Science Foundation (20040350410) and the Talent Program of the Cold and Arid Regions Environmental and Engineering Research Institute, CAS. Wavelet software was provided by C. Torrence and G. Compo, and is available at http://paos.colorado.edu/research/wavelets/

\section{REFERENCES}

Baliunas, S., P. Frick, D. Sokoloff and W. Soon. 1997. Time scales and trends in the Central England Temperature data (1659-1990): a wavelet analysis. Geophys. Res. Lett., 24(11), 1351-1352.
Biondi, F., C. Isaacs, M.K. Hughes, D.R. Cayan and W.H. Berger. 2000. The near-1600 dry/wet knock-out: linking terrestrial and near-shore ecosystems. In Proceedings of the 24th Annual Climate Diagnostics and Prediction Workshop. Springfield, VA, US Department of Commerce, 76-79.

Cook, E.R., D.M. Meko, D.W. Stahle and M.K. Cleaveland. 1996. Tree-ring reconstructions of past drought across the coterminous United States: tests of a regression method and calibration/ verification results. In Dean, J.S., D.M. Meko and T.W. Swetnam, eds. Tree rings, environment, and humanity. Tucson, AZ, Radiocarbon, 155-169.

Daubechies, I. 1992. Ten lectures on wavelets. Second edition. Philadelphia, PA, Society for Industrial and Applied Mathematics.

Farge, M. 1992. Wavelet transforms and their applications to turbulence. Ann. Rev. Fluid Mech., 24, 395-457.

Foufoula-Georgiou, E. and P. Kumar, eds. 1995. Wavelets in geophysics. Beijing, Academic Press.

Gamage, N. and W. Blumen. 1993. Comparative analysis of low-level cold fronts: wavelet, Fourier, and empirical orthogonal function decompositions. Mon. Weather Rev., 121(10), 2867-2878.

Gou, X., F. Chen, M. Yang, J. Li, J. Peng and L. Jin. 2005. Climatic response of thick leaf spruce (Picea crassifolia) tree-ring width at different elevations over Qilian Mountains, northwestern China. J. Arid Environ., 61(4), 513-524.

Gou, X., F. Chen, G. Jacoby and M. Yang. 2006. A comparison of tree-ring records and glacier variations over the past 700 years, northeastern Tibetan Plateau. Ann. Glaciol., 43 (see paper in this volume).

Gu, D. and S.G.H. Philander. 1995. Secular changes of annual and interannual variability in the Tropics during the past century. J. Climate, 8(4), 864-876.

Hansen, J. and S. Lebedeff. 1987. Global trends of measured surface air temperature. J. Geophys. Res., 92(D11), 13,345-13,372.

Holschneider, M. 1995. Wavelets: an analysis tool. New York, Oxford University Press.

Jevrejeva, S., J.C. Moore and A. Grinsted. 2003. Influence of the Arctic Oscillation and El Niño-Southern Oscillation (ENSO) on ice conditions in the Baltic Sea: the wavelet approach. J. Geophys. Res., 108(D21), 4677. (10.1029/2003JD003417.)

Li, Y., T. Yao and C. Huang. 1993. The chemical components spatial distribution on the Guliya ice cap. J. Glaciol. Geocryol., 15(3), 467-473. [In Chinese with English abstract.]

Li, Z., T. Yao and Z. Xie. 1994. The modern atmospheric environmental records in Guliya ice core, Tibetan Plateau. Chinese Sci. Bull., 39(23), 2200-2201. 
Liu, P.C. 1995. Wavelet spectrum analysis and ocean wind waves. In Foufoula-Georgiou, E. and P. Kumar, eds. Wavelets in geophysics. Beijing, Academic Press, 151-166.

Meyers, S.D., B.G. Kelly and J.J. O'Brien. 1993. An introduction to wavelet analysis in oceanography and meteorology: with application to the dispersion of Yanai waves. Mon. Weather Rev., 121(10), 2858-2866.

Shi, Y., T. Yao and B. Yang. 1999. Decadal climatic variations recorded in Guliya ice core and comparison with the historical documentary data from East China during the last 2000 years. Sci. China D, 42(Supp.), 91-100.

Taylor, K., M. Rose and G. Lamorey. 1992. Relationship of solar activity and climatic oscillations on the Colorado Plateau. J. Geophys. Res., 97(D14), 15,803-15,811.

Thompson, L.G. and 9 others. 1989. Holocene-Late Wisconsin Pleistocene climatic ice core records from Qinghai-Tibetan Plateau. Science, 246(4929), 474-477.

Thompson, L.G. and 6 others. 1995. A 1000 year climatic ice-core record from the Guliya ice cap, China: its relationship to global climate variability. Ann. Glaciol., 21, 175-181.

Thompson, L.G. and 9 others. 1997. Tropical climate instability: the last glacial cycle from a Qinghai-Tibetan ice core. Science, 276(5320), 1821-1825.

Thompson, L.G., T. Yao, E. Mosley-Thompson, M.E. Davis, K.A. Henderson and P. Lin. 2000. A high-resolution millennial record of the south Asian monsoon from Himalayan ice cores. Science, 289(5486), 1916-1919.

Torrence, C. and G.P. Compo. 1998. A practical guide to wavelet analysis. Bull. Am. Meteorol. Soc., 79, 61-78.

Torrence, C. and P.J. Webster. 1999. Interdecadal changes in the ENSO-monsoon system. J. Climate, 12, 2679-2690.

Villaba, R. and 6 others. 1996. Interdecadal climatic variations in millennial temperature reconstructions from southern South America. In Jones, P.D., R.S. Bradley and J. Jouzel, eds. Climatic variations and forcing mechanisms of the last 2000 years. Berlin, Springer, 161-189. (NATO ASI Series 141.)
Wang, B. and Y. Wang. 1996. Temporal structure of the Southern Oscillation as revealed by waveform and wavelet analysis. J. Climate, 9(7), 1586-1598

Weng, H. and K.-M. Lau. 1994. Wavelets, period doubling, and time-frequency localization with application to organization of convection over the tropical western Pacific. J. Atmos. Sci., 51(17), 2523-2541.

Yang, B., A. Braeuning, K.R. Johnson and S. Yafeng. 2002. General characteristics of temperature variation in China during the last two millennia. Geophys. Res. Lett., 29(9), 1324. (10.1029/ 2001GL014485.)

Yang, M., T. Yao, Y. He and L.G. Thompson. 2000. ENSO events recorded in the Guliya ice core. Climatic Change, 47(4), 401-409.

Yao, T. and L.G. Thompson. 1992. Trends and features of climatic changes in the past 5000 years recorded by the Dunde ice core. Ann. Glaciol., 16, 21-24.

Yao, T., Z. Xie, X. Wu and L.G. Thompson. 1990. Climatic records since the Little Ice Age from the Dunde Ice Cap. Sci. China B, 20(11), 1196-1201.

Yao, T., Z. Yang and J. Lu. 1994. The warming in Tibetan Plateau revealed by ice core records. Chinese Sci. Bull., 39(5), 438-441.

Yao, T., L.G. Thompson, K. Jiao, E. Mosley-Thompson and Z. Yang. 1995. Recent warming as recorded in the Qinghai-Tibetan cryosphere. Ann. Glaciol., 21, 196-200.

Yao, T., D. Qin and L. Tian. 1997. The variations of the temperature and precipitation in the past $2 \mathrm{ka}$ in Tibetan Plateau - Guliya ice core records. Sci. China D, 39(4), 425-433.

Yao, T., L.G. Thompson, Y. Shi, D. Qin and K. Jiao. 1997. Climatic variation since the last interglacial recorded in the Guliya ice core. Sci. China D, 40(6), 662-668.

Yao, T., B. Xu and J. Pu. 2001. Climatic changes on orbital and suborbital time scale recorded by the Guliya ice core in Tibetan Plateau. Sci. China D, 43(Suppl.), 360-369.

Yao, T. and 7 others. 2002. Temperature and methane changes over the past 1000 years recorded in Dasuopu glacier (central Himalaya) ice core. Ann. Glaciol., 35, 379-383. 